\title{
Hospital waste generation during the first wave of COVID-19 pandemic: a case study in Delhi
}

\author{
Mayank Singh $^{1} \cdot$ Nima Karimi $^{1} \cdot K_{\text {Kelvin Tsun Wai Ng}}{ }^{1}$ (D) $\cdot$ Derek Mensah $^{1} \cdot$ Denise Stilling $^{2} \cdot$ Kenneth $^{\text {Adusei }}{ }^{1}$
}

Received: 21 December 2021 / Accepted: 24 February 2022 / Published online: 3 March 2022

(c) The Author(s), under exclusive licence to Springer-Verlag GmbH Germany, part of Springer Nature 2022

\begin{abstract}
In this study, the hospital waste generation rates and compositions in Delhi were examined temporally and spatially during the first COVID-19 wave of April 2020. A total of 11 representative hospitals located in five districts were considered. The pre-COVID hospital waste generation rates were relatively consistent among the districts, ranging from 15 to 23 tonne/ month. It is found that the number of hospital beds per capita may not be a significant factor in the hospital waste quantity. Strong seasonal variations were not observed. All districts experienced a drastic decrease in generation rates during the 1-month lockdown. The average rates during the COVID period ranged from 12 to 24 tonne/month. Bio-contaminated and disposable medical product wastes were the most common waste in Delhi's hospitals, representing 70-80\% by weight. The changes in waste composition were however not spatially consistent. The lockdown appeared to have had a higher impact on hospital waste generation rate than on waste composition. The findings are important as the design and operation of a waste management system are sensitive to both waste quantity and quality. Waste records at source helped to minimize waste data uncertainties and allowed a closer examination of generation trends.
\end{abstract}

Keywords Hospital waste management · Waste generation rates · Waste composition · Temporal analysis · COVID-19 . Developing countries

\section{Introduction and literature review}

\section{Municipal solid waste management during the pandemic}

The global spread of the SARS-CoV-2 virus and the resulting COVID-19 pandemic have introduced new challenges to solid waste management that require prompt responses from policy makers and waste researchers (Purnomo et al., 2021; Richter et al., 2021b; Vu et al., 2021b). These challenges relate to the significant increase in personal protective

Responsible Editor: Philippe Garrigues

Kelvin Tsun Wai Ng

kelvin.ng@uregina.ca

1 Environmental Systems Engineering, Faculty of Engineering and Applied Science, University of Regina, Regina, SK S4S 0A2, Canada

2 Industrial Systems Engineering, Faculty of Engineering and Applied Science, University of Regina, Regina, SK S4S 0A2, Canada equipment (PPE) and COVID-19-related medical wastes and hazardous materials (Hantoko et al., 2021; Torres and De-la-Torre 2021; Valizadeh et al., 2021). For example, Silva et al. (2020) stated the importance of plastic policy readjustments during the COVID-19 pandemic due to the elevated use of single-use plastic and other PPE. Wang et al. (2021b) concluded that the improper disposal of PPE may eventually enter the marine environment and release microplastics, once ingested by aquatic fauna becomes part of the human food chain. During a pandemic, additional waste collection services and special management measures are typically required to protect public health and the environment (Ilyas et al., 2020; Yang et al., 2021). Studies on different methods on proper monitoring, handling, and treatment of abnormal patterns of waste streams during the pandemic have been recently reported (Purnomo et al., 2021; Richter et al., 2021a; Vu et al. 2021a).

The literature suggests that the effects of the pandemic on municipal solid waste generation characteristics and recycling behaviors are region-specific, probably due to the drastic differences in regulations and enforcement, hygiene protocols, living standards, and other socioeconomic-religious 
factors. According to a survey, conducted by the Association of Cities and Regions for Sustainable Resources management (ACRPLUS 2021), a general decrease in municipal solid waste generation rates in 10 European countries was observed during the first wave of the COVID-19 pandemic from February to June 2020. Similar decreasing trends during the first wave were reported in cities in China (Kulkarni and Anantharama 2020) and Canada (Richter et al. 2021b). On the contrary, Elsaid et al. (2021) reviewed studies on the effects of COVID-19 on the environment and reported that municipal solid waste generation increased both qualitatively and quantitatively from the literature. An increase in waste generation during the COVID-19 pandemic in Brazil was also predicted by Penteado and Castro (2021).

\section{Data-driven waste policy on medical and healthcare wastes}

Unlike municipal solid waste, the generation characteristics of medical and healthcare wastes are globally more consistent during the pandemic. Published studies generally reported an elevated amount of medical and healthcare waste which are likely due to the disposing of PPE such as gloves, masks, gowns, and face shields (Chen et al. 2021; Hantoko et al. 2021; Olatayo et al. 2021). Given the nature of these wastes, special treatment methods are typically required (Purnomo et al., 2021). Das et al. (2021) reviewed published studies and reported challenges associated with the storage, recycling, and treatment of solid wastes from healthcare facilities, medical laboratories, and biomedical research facilities. According to Keller et al. (2021), hospitals are the main contributor to environmental impacts, generating an average carbon footprint of 3.2 tonnes $\mathrm{CO}_{2}$-eq per functional unit. However, specific studies on hospital waste management are very limited (Dias-Ferreira et al. 2015; Fletcher et al., 2021). Given the additional PPE waste and the elevated hygiene protocol during the pandemic, more solid waste is expected from hospitals and health institutions (Al-Omran et al. 2021; Wang et al. 2021a). As such, a specific study on the waste generation characteristics from hospitals is urgently needed.

Data accuracy and reliability is a key challenge in the development of an evidence-based waste management system (Richter et al. 2019; Ghosh and Ng, 2021), especially during the pandemic. For example, different modeling approaches such as the uses of lagged inputs and distinct time series ( $\mathrm{Vu}$ et al. 2021a) and separated waste fractions (Vu et al. 2021b) were attempted to minimize uncertainties in data and variations in waste recycling behaviors during the COVID pandemic. Proper storage, treatment, and disposal of healthcare wastes also require accurate and precise waste data (Fletcher et al., 2021; Manupati et al. 2021). Most of the studies aggregated waste data from research and medical laboratories with hospitals, making it difficult to interpret the differences in waste generation trends between the development and the application of medical science. Working directly with waste records from hospitals helps to minimize data uncertainties, leading to better resource management during the pandemic. Ganguly and Chakraborty (2021) reported that there is a lack of COVID waste studies in developing countries, particularly in India. Most published studies focus on general biomedical waste management in India (Ramteke and Sahu, 2020; Chand et al. 2021; Thind et al. 2021); however, none of the published studies specifically examine generation and composition characteristics of hospital wastes. As further discussed in Sect. 1.3 , this case study aims to address the temporal and spatial changes of hospital wastes during the first COVID wave in Delhi, India.

\section{Study objective, novelty, and study area}

The key objective of this case study is to investigate and analyze hospital solid waste generation rates in Delhi, both temporally and spatially during the first COVID-19 wave. This study fills the knowledge gap on hospital waste generation characteristics (quantity and quality) in the capital city of India during this global pandemic. It is hypothesized that the use of waste records from hospitals will help to minimize data uncertainties, allowing a better distinction of COVID waste generation trends between hospitals and medical research labs. The results will assist with the development of data-driven hospital waste management policies for developing countries.

As of October 20, 2021, India has the highest reported COVID cases (34.1 million cases) and mortalities $(452,800)$ in Asia (Worldometers, 2021a). The total Indian population was estimated at 1.38 billion in 2020 , representing about $17.7 \%$ of the world's population (Worldometers, 2021a). Delhi, the capital city of India, is selected as the study area. Among major Indian cities, Delhi was one of the most affected cities by COVID-19 (Chand et al. 2021; Ramteke and Sahu, 2021). Delhi has an estimated population of over 31 million in its greater metropolitan area (Worldpopulationreview, 2021), with a population density of about $563 \mathrm{cap} /$ $\mathrm{km}^{2}$. Prior to lockdown, Somani et al. (2020) reported the quantity of waste reaching Delhi dumpsites ranged between 3,000 and 3,700 MT/day.

\section{Methodology}

Different regulations were enforced by various levels of governmental agencies in Delhi during the COVID period. The city lockdown generally lasted about a month, from April to May 2020. Different parts of the city were subjected to 
additional restrictions. Given the nature of the pandemic, it is difficult to precisely define the beginning of the COVID period in Delhi. For data analysis purposes, the COVID period is defined from April 2020 onward. Both the preCOVID period and COVID period are considered.

In this study, waste generation and management data from hospitals in five districts (Central, North, East, South, and West) in Delhi were collected, verified, and consolidated. Biomedical waste originated from scientific research labs and testing facilities were intentionally omitted. Smaller clinics such as nurse-led community clinics and private health centers were not considered, as reliable waste records are not available. A total of 11 major hospitals or health institutions were selected, with data ranges varying from 25 to 53 months. Although the size of the selected hospitals or health institutions are not identical, all of them provide comparable ranges of services and facilities during the study period. The 11 hospitals are believed to be representative of the health care system in Delhi. Figure 1 shows the locations of the hospitals. With the exception of the central district (the least populated), each district has at least two hospitals. The use of waste generation data at the sources rather than the agglomerated data at the regional level allows examining waste generation characteristics and recycling behaviors with a higher degree of precision and certainty.

The populations of the five selected districts are not similar (Table 1). The central district is the least populated with less than a million habitants; whereas, the North District is the most populated with nearly 7 million habitants. The monthly waste generated per bed in the selected hospitals is quite consistent, ranging from 33.4 to $42.0 \mathrm{~kg} / \mathrm{bed}$, as discussed further in Sect. 3. Al-Khatib et al. (2020) reported a similar range of 16.4 to $55.4 \mathrm{~kg} / \mathrm{bed}(0.54$ to $1.82 \mathrm{~kg} /$ bed-day) in the three hospitals in the Jenin district, Palestine. Similar ranges are also reported by Agamuthu and Barasarathi (2021). To establish the baseline and to examine the

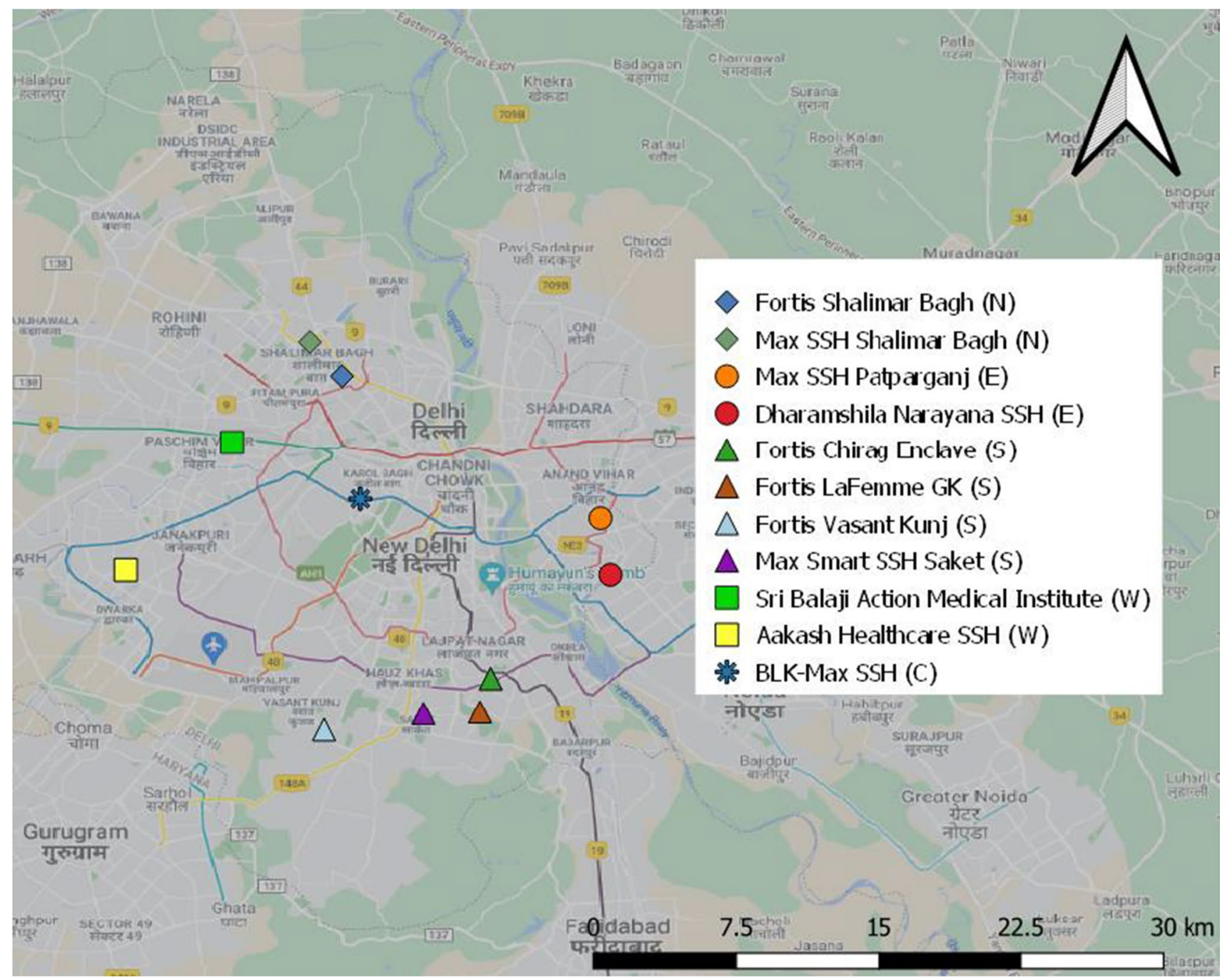

Fig. 1 Selected hospitals in five districts in Delhi 
Table 1 Hospital waste generation characteristics in five districts in Delhi

\begin{tabular}{|c|c|c|c|c|c|}
\hline & Central & East & West & South & North \\
\hline $\begin{array}{l}\text { District population (in } \\
\text { millions) }\end{array}$ & 0.7 & 1.7 & 2.5 & 5.0 & 6.8 \\
\hline $\begin{array}{l}\text { Major hospitals selected } \\
\text { in the district }\end{array}$ & BLK Max & $\begin{array}{l}\text { Max Patparganj, Dhar- } \\
\text { amshila Narayana } \\
\text { SSH }\end{array}$ & $\begin{array}{l}\text { Sri Balaji Action Medi- } \\
\text { cal Institute, Aakash } \\
\text { Healthcare SSH }\end{array}$ & $\begin{array}{l}\text { Fortis Chirag Enclave, } \\
\text { Fortis LaFemme GK, } \\
\text { Fortis Vasant Kunj, } \\
\text { Max Smart SSH } \\
\text { Saket }\end{array}$ & $\begin{array}{l}\text { Fortis Shalimar Bagh, } \\
\text { Max SSH Shalimar } \\
\text { Bagh }\end{array}$ \\
\hline $\begin{array}{l}\text { Average monthly waste } \\
\text { during the entire } \\
\text { period (kg/month) }\end{array}$ & 19,321 & 22,087 & 16,806 & 16,049 & 18,511 \\
\hline $\begin{array}{l}\text { Number of hospital } \\
\text { beds provided in the } \\
\text { district }\end{array}$ & 465 & 602 & 400 & 480 & 462 \\
\hline Beds per million people & 664.3 & 354.1 & 160.0 & 96.0 & 67.9 \\
\hline $\begin{array}{l}\text { Monthly hospital waste } \\
\text { per bed (kg/bed) }\end{array}$ & 41.6 & 36.7 & 42.0 & 33.4 & 40.1 \\
\hline $\begin{array}{l}\text { Data collection period } \\
\text { (months) }\end{array}$ & $\begin{array}{l}\text { Jan 2017- } \\
\text { Apr } 2021 \\
\text { (52 months) }\end{array}$ & $\begin{array}{l}\text { Jan 2018-Feb } 2021 \\
\quad(38 \text { months })\end{array}$ & $\begin{array}{l}\text { Jan 2019-Jan } 2021 \\
\quad(25 \text { months })\end{array}$ & $\begin{array}{l}\text { Jan 2017-May } 2021 \\
\text { (53 months) }\end{array}$ & $\begin{array}{l}\text { Jan 2017-Apr } 2021 \\
\quad(52 \text { months })\end{array}$ \\
\hline
\end{tabular}

potential impacts of the pandemic on hospital waste generation, data starting from January 2017 was included. Table 1 provides details of the collected data, which includes naming individual hospitals in each district, the characteristics of the monthly hospital waste generation, and the data ranges.

Due to the heterogeneous nature of hospital solid wastes (dressings, cotton swabs, syringes, soiled gloves, catheters, and other wastes), the analysis of waste quantity by weight can be misleading given the differences in waste densities and moisture content. As such, the hospital waste compositions were also examined. Waste segregation is conducted by hospital staff at the source. Waste from each of the 11 hospitals is disposed of in color-coded waste bins, and the hospital's historical waste records were used to compute the waste composition. The five distinct categories are defined in Table 2. Yellow (biomedical waste) and red (disposable medical supplies) are the most common waste in Delhi's hospitals. Typically, they represent $70-80 \%$ of the waste by weight, as discussed further in Sect. 3.3.

Waste composition data was calculated from monthly reports prepared by individual hospitals, often under inconsistent waste definitions, reporting periods, and data formats. This public data from the 11 selected hospitals were meticulously processed, cross-referenced, and verified. Temporal changes of hospital waste generation rates were examined spatially with respect to individual districts before and during the first wave in April 2020. Stacked bar charts were used to examine the changes in waste composition over time. Each bar represents the total waste as $100 \%$ with the segments representing each waste component.

Table 2 Hospital waste composition in the five districts in Delhi

\begin{tabular}{ll}
\hline Category & Waste composition \\
\hline Yellow & $\begin{array}{l}\text { Biomedical waste includes all dressings and bandages with body fluids, blood bags, human anatomical waste, body parts, etc. } \\
\text { Cotton swabs used extensively for the real-time polymerase chain reaction (RT-PCR) tests for the SARS-CoV-2 belong to this } \\
\text { category }\end{array}$ \\
Red & $\begin{array}{l}\text { Disposable medical supplies, including syringes (without needles), soiled gloves, used face shields, catheters, IV tubes, etc } \\
\text { Blue }\end{array}$ \\
Cytotoxic & $\begin{array}{l}\text { Any material contaminated with residues or preparations that are toxic to cells and are considered hazardous as these wastes are } \\
\text { capable of impairing, injuring, or killing cells and can cause toxic or allergic reactions }\end{array}$ \\
White/Sharp & Needles, sharps, blades, or any kind of tool or object that is able to puncture or cut the skin
\end{tabular}




\section{Results and discussion}

\section{Hospital waste generation rates before the COVID period}

Temporal changes of hospital waste generation in all five districts are shown in Fig. 2. The date ranges of the curves are not constant; this is due to incomplete data availability (Table 1). Figure 2 shows that the generation rates were quite consistent during the pre-COVID period from January 2017 to March 2020; the generation rates were between 15 to 23 tonne/month. The east district (shown as the blue curve in Fig. 2) consistently produced more hospital wastes than the other districts, with an average of 21.94 tonne/month pre-COVID. This may be due to the east district having the highest number of hospital beds among the districts (i.e., 602 beds as given in Table 1). Pre-COVID waste generation rates are similar between the central (the orange curve in Fig. 2) and the north (the yellow curve in Fig. 2), despite a tenfold difference in the number of beds per capita ( 664.3 beds/million vs. 67.9 beds/million as given in Table 1). These results suggest that the number of hospital beds per capita may not be a significant factor in the amount of hospital waste generated in Delhi. This is important as many COVID healthcare waste modeling studies have used beds per capita as a dependent input. On average, the south district produced the least amount of waste pre-COVID at about 16.39 tonne/month.

\section{Hospital waste generation rates during the first wave of COVID in Delhi}

Unlike a Canadian study of municipal waste disposal during the first wave of COVID (Richter et al. 2021a), strong seasonal variations of the hospital waste generation rates were not observed, and the hospital waste generation trends in India appear insensitive to the different seasons. Seasonal variations in municipal waste disposal rate appear as an important parameter in some COVID waste modeling studies (Vu et al. 2021a, b). It appears that hospital waste generation trends are less affected by the time of the year.

As shown in Fig. 2, hospital waste generation in all districts was more erratic during the COVID period. The lockdown of most regions in Delhi began on April 1, 2020, as indicated by the red vertical line in Fig. 2. With the exception of the central district (the orange curve), all districts experienced a sharp decrease in waste generation rates between March 2020 and April 2020. For example, the west district generation rate experienced a $48.3 \%$ reduction (the gray curve), dropping from 19.01 tonne/month to 9.82 tonne/month. The decreasing trend could be attributed to (i)

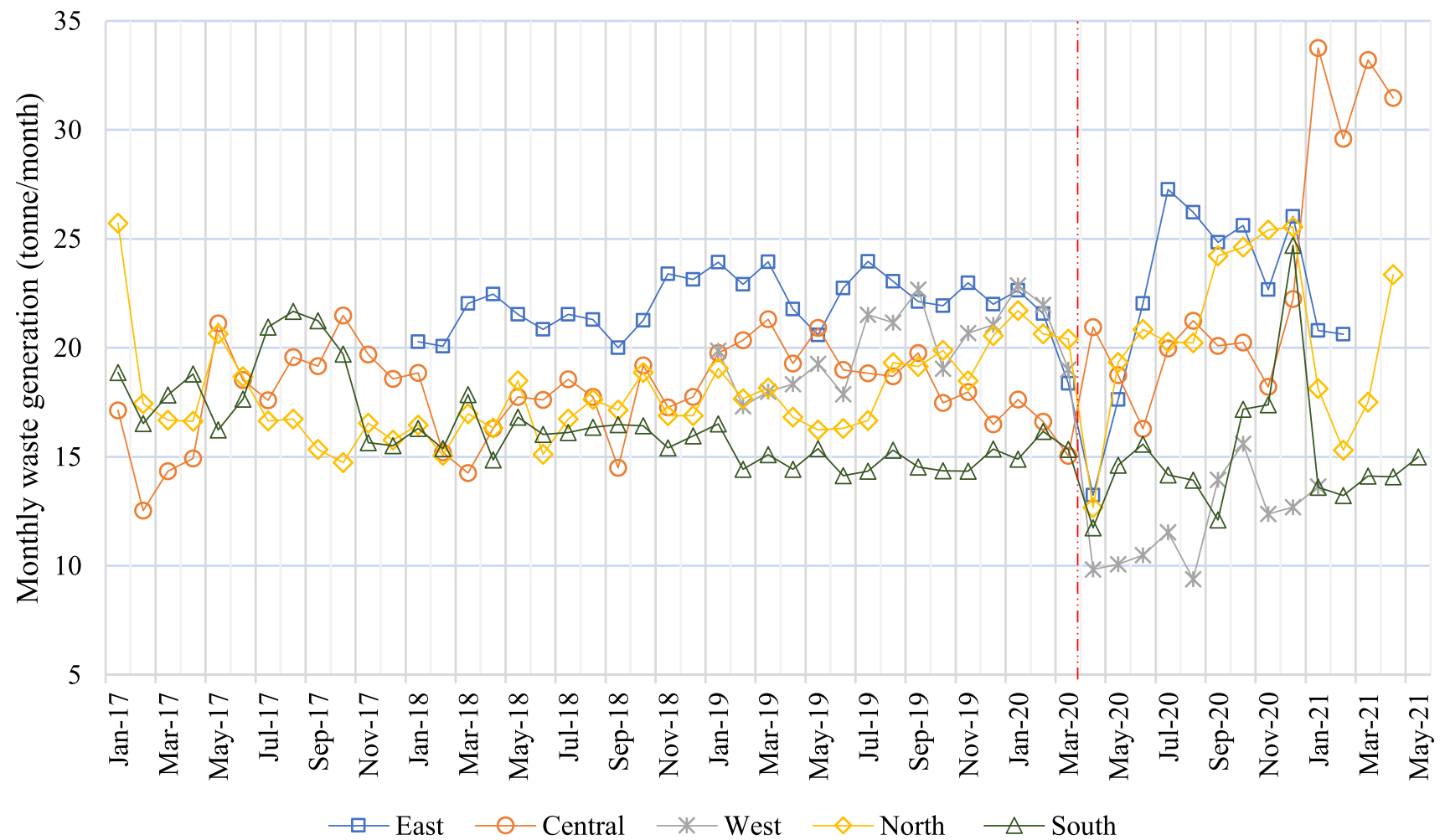

Fig. 2 Hospital waste generation rates in the five districts from 2017 to 2021 
people avoiding hospitals for minor illnesses due to fear of contracting COVID, (ii) restricted access to hospitals due to the newly enforced regulations, and/or (iii) the reduced injury rate due to the lifestyle changes as a work-from-home recommendation and slowed economic activities occurred (Richter et al. 2021b). Somani et al. (2020) also reported a $20-40 \%$ reduction in waste disposal rates in 10 Indian landfills/dumpsites during the lockdown. Richter et al. (2021a) found similar results in treated biomedical waste disposal in Regina, the capital city of Saskatchewan, Canada during the city's lockdown. Another possible explanation could be due to a decrease in airborne infectious disease cases other than COVID-19 as mask-wearing became mandatory, and more stringent personal hygiene protocols were promoted during the 1-month lockdown.

Unlike other districts, hospital waste generation in the central district (the orange curve) increased from 15.04 tonne/month in March to 20.95 tonne/month in April 2020. This $39.3 \%$ increase in hospital waste during the lockdown in the central district may be explained by the popularity of the health institution. Since the central district is represented by a single major hospital (BLK Max as stated in Table 1), many COVID-19 case consultations were conducted at this location as sophisticated equipment, well-trained staff, and higher hygiene standards exist are available. BLK Max is the largest stand-alone private sector hospital in Delhi. This hospital has a large capacity with an abundancy of available beds ( 664.3 beds per million people as shown in Table 1). These factors have the potential to attract more patients than other hospitals resulting in increased waste generation.

During the COVID period from Apr 2020 to Mar 2021, all five districts consistently experienced larger variations in hospital waste generation. The average generation rates in central, east, west, south, and north districts during the COVID period are calculated as 23.5, 22.5, 12.0, 15.1, and 20.6 tonne/month, respectively. The west district produced the highest amount of waste per bed during the entire period (Table 1) yet experienced the largest reduction in hospital waste after the lockdown (as shown by the grey curve in Fig. 2). The fluctuations in hospital waste generation rates during the first wave of COVID could be due to multiple contrasting factors. The streamlined effect for the COVID-19 vaccination and treatment processes (Richter et al. 2021a), as well as for the efficient use of PPE (Wang et al. 2021b), may have reduced the waste generation. Accurate and publically available vaccination records in the study area during the period are however not available. On the other hand, there was a rapid increase in COVID cases during the first wave in Delhi. In addition, people returned to hospitals for illnesses and surgeries that had to be postponed during the April 2020 lockdown. Studies indicated that the overall biomedical waste (including hospital wastes) in India increased during the COVID period (Chand et al. 2021; Thind et al.
2021). Since COVID-related waste required special handling and treatment processes (Ilyas et al. 2020; Al-Omran et al. 2021), modeling studies on hospital waste are recommended.

\section{Hospital waste composition in Delhi}

The stacked bar chart illustrated in Fig. 3 was used for analyzing the variations of hospital waste composition in each district from January 2020 to January 2021. The 13-month period immediately before, during, and after the lockdown is selected to examine the possible effects of the pandemic on hospital waste composition. Biomedical waste (yellow) and disposable medical supplies (red) are the major waste components in all five districts; together they represent approximately $80-85 \%$ of all hospital waste by weight (Fig. 3). On the contrary, there were minimum cytotoxic materials, contributing less than $1 \%$ of the total weight.

From January to March 2020, the waste composition in each respective district was nearly constant prior to the lockdown. Obvious changes in hospital waste composition are observed in all districts during and after the lockdown in April and May 2020. However, the changes of waste compositions are more subtle in the south district (as shown in Fig. 3e). The south district traditionally has the least waste per bed among the districts $(33.4 \mathrm{~kg} / \mathrm{bed}$ as shown in Table 1) and appears to be less sensitive to the lockdown.

The changes in waste composition are not spatially consistent. Higher percentages of disposable medical waste (red waste) such as syringes and soiled gloves are observed in the east district (Fig. 3a) and to a lesser degree in the south district (Fig. 3e). The east and south districts have the highest number of beds (Table 1) and also have the higher capacities to administer vaccinations and care for the patients on a daily basis. Higher percentages of biomedical waste such as cotton swabs are observed in the central and north districts (yellow bars in Fig. 3b and d). The higher biomedical waste generation rate is probably originating from the cotton swabs used in the real-time polymerase chain reaction (RT-PCR) tests for the SARS-CoV-2. As previously discussed, the central district is home to a large and popular private hospital. The north district has the largest client base and serves nearly 7 million people (Table 1). The popularity of the institution and a broad clientele may contribute to the higher hospital waste generation during the lockdown.

An unusually high amount of medical glass waste at $22.9 \%$ is observed in May 2020 in the west district (represented by the blue bar in Fig. 3c). This may have originated from the glass vials used in the laboratory testing for sample processing and dilution; however, no direct evidence is available from the hospital records to support this claim.

Fig. 3 Changes of waste composition from January 2020 to January 2021 in the a east, $\mathbf{b}$ central, $\mathbf{c}$ west, $\mathbf{d}$ north, and $\mathbf{e}$ south districts 
a

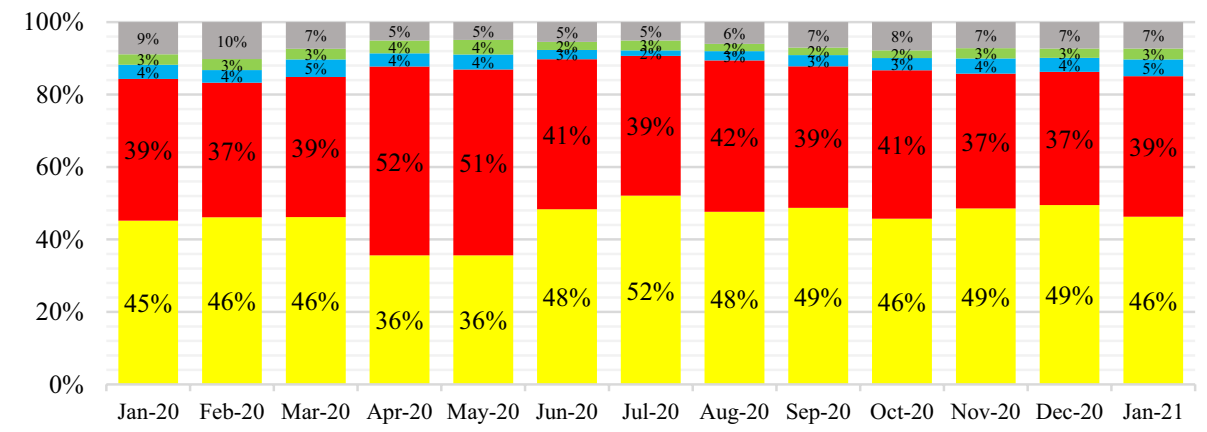

b

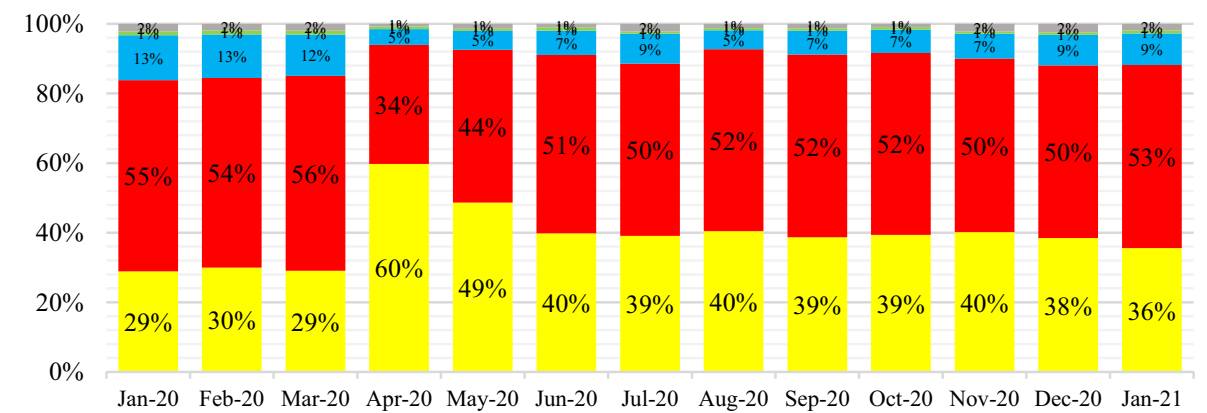

$$
100 \%
$$

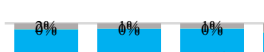

$80 \%$

$60 \%$

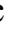

$40 \%$

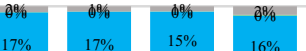

$-17 \%$
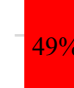

$20 \%$
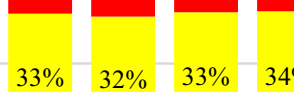

Jan-20 Feb-20 Mar-20 Apr-20 May-20 Jun-20 Jul-20 Aug-20 Sep-20 Oct-20 Nov-20 Dec-20 Jan-21

d

$$
\begin{array}{r}
100 \% \\
90 \% \\
80 \% \\
70 \% \\
60 \% \\
50 \% \\
40 \% \\
30 \%
\end{array}
$$

$100 \%$

$90 \%$

$80 \%$

$70 \%$

$60 \%$

$50 \%$

$40 \%$

$30 \%$

$10 \%$

$0 \%$

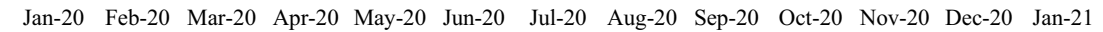

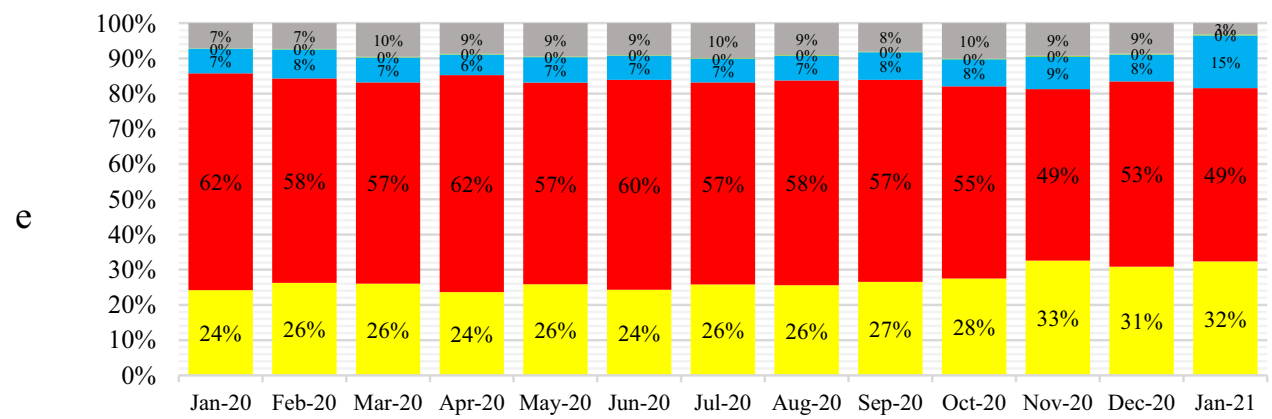

White/Sharp

Cytotoxic

Blue

- Red

Yellow

\section{- White/Sharp \\ Cytotoxic \\ Blue \\ - Red \\ Yellow}

White/Sharp
Cytotoxic
$\square$ Blue
$\square$ Red
Yellow

White/Sharp

Cytotoxic

Blue

Red

Yellow 
Unlike the erratic, post-lockdown generation rates shown in Fig. 2, the waste compositions are much more consistent after the lockdown. For example, the waste compositions in all districts stabilized in 4 to 5 months and were relatively constant from September 2020 to January 2021. The waste compositions were also comparable to the pre-COVID values (Fig. 3). COVID-19 awareness among the Delhi citizens during the lockdown may help residents to get accustomed to the pandemic and better prepare them for the smooth emerging from the pandemic. This increased awareness was reflected in the hospital waste composition. The composition results suggest that the overall healthcare system in Delhi is quite resilient. The selected 11 hospitals, representing the Delhi health care system, were able to accommodate the rise of COVID cases without seriously impacting their key operations and altering the waste composition.

The results suggested that the hospital waste generation rate is more sensitive to the lockdown than waste composition. These findings have important practical implications. The waste composition data may impact the selection of waste collection routes ( $\mathrm{Vu}$ et al. 2020) or treatment processes (Purnomo et al. 2021; Valizadeh et al. 2021). Ultimately, the increase in generation rates will affect scaling the waste disposal infrastructure and requirements along with policies for site selection and disposal methods.

\section{Conclusions}

The literature review suggests a lack of published studies on the generation characteristics of hospital wastes in developing countries. In this study, the hospital solid waste generation rates and the composition in Delhi, the capital city of India, are examined temporally and spatially during the first COVID-19 wave of April 2020. A total of 11 representative hospitals located in five districts with comparable ranges of services and facilities were considered. The monthly waste generation per bed ranged from 33.4 to $42.0 \mathrm{~kg} / \mathrm{bed}$.

The pre-COVID generation rates in all districts were relatively consistent, ranging from 15 to 23 tonne/month. Specifically, the waste generation rates are similar between the central and the north despite a tenfold difference in the number of beds per capita. The results suggest that the number of hospital beds per capita may not be a significant factor in the quantity of hospital waste. Strong seasonal variations of the hospital waste generation rates were not observed.

All districts experienced a sharp decrease in waste generation rates during the 1-month lockdown. This may be contributed by the economic lockdown and drastic change in lifestyle. No significant variations were observed during the COVID period from April 2020 to March 2021. All five districts experienced large variations in hospital waste generation due to multiple factors. The average generation rates during the COVID period ranged from 12.0 to 23.5 tonne/month. Since COVID-related waste required special handling and treatment processes, advanced modeling studies on hospital waste quantity are recommended.

Yellow (bio-contaminated) and red (disposable medical product) wastes are the most common waste in Delhi's hospitals, representing $70-80 \%$ of the waste by weight. Similar hospital waste compositions were observed in all districts prior to the lockdown. Observable changes in composition occurred in all districts during and after the lockdown. The changes in waste composition were not spatially consistent, and higher percentages of disposable medical waste were observed in the east district. Unlike the erratic, post-lockdown generation rates, the waste compositions were much more consistent after the lockdown. The consistency in hospital waste composition suggests that the overall healthcare system in Delhi is quite resilient, based on the data from the 11 selected hospitals. The lockdown appeared to have had a higher impact on hospital waste generation rate with the hospital percentage of waste composition being relatively consistent. These findings are important for future pandemics, as the design and operation of the transportation, storage, and treatment are sensitive to the waste amount and composition.

This study addresses the knowledge gap on hospital waste generation characteristics; both the quantity and quality that occurs during a global pandemic. In conclusion, the waste records at the source helped to minimize data uncertainties and allowed a better distinction of COVID waste generation trends occurring in hospitals in India.

Acknowledgements The authors are grateful for the support from the funding agencies. The views expressed herein are those of the writers and not necessarily those of our research and funding partners.

Author contribution Mayank Singh: conceptualization; writing-original draft; Nima Karimi, writing — original draft, formal analysis; Kelvin Tsun Wai Ng, writing - original draft, investigation, supervision, project administration; Derek Mensah, writing_-review and editing; Denise Stilling, writing - review and editing; Kenneth Adusei, writing-review and editing.

Funding The research reported in this paper was supported by a grant from the Natural Sciences and Engineering Research Council of Canada (RGPIN-2019-06154) to the corresponding author, using computing equipment funded by FEROF at the University of Regina. The lead author (M. Singh) was also supported by a Mitacs Globalink research award.

Data availability All data generated or analyzed during this study are included in this article.

\section{Declarations}

Ethics approval Not applicable 
Consent to participate Not applicable.

Consent for publication Not applicable.

Competing interests The authors declare no competing interests.

\section{References}

ACRPLUS ( 2021) The impact of the COVID-19 pandemic on municipal waste management systems. Published by Association of Cities and Regions for Sustainable Resources management. Accessed on Oct 20, 2021. Available at https://acrplus.org/images/techn ical-reports/2021_ACR_Impact_COVID-19_pandemic_on_munic ipal_waste_management_systems.pdf

Agamuthu P, Barasarathi J (2021) Clinical waste management under COVID-19 scenario in Malaysia. Waste Manag Res 39:18-26. https://doi.org/10.1177/0734242X20959701

Al-Khatib IA, Khalaf A, Al-Sari MI, Anayah F (2020) Medical waste management at three hospitals in Jenin district Palestine. Environ Monit Assess 192:10. https://doi.org/10.1007/s10661-019-7992-0

Al-Omran K, Khan E, Ali N, Bilal M (2021) Estimation of COVID-19 generated medical waste in the Kingdom of Bahrain. Sci Total Environ 801:149642. https://doi.org/10.1016/j.scitotenv.2021. 149642

Chand S, Shastry C, Hiremath S, Joel JJ, Krishnabhat C, Mateti UV (2021) Updates on biomedical waste management during COVID-19: the Indian scenario. Clin Epidemiology Glob Health 11:100715. https://doi.org/10.1016/j.cegh.2021.100715

Chen C, Chen J, Fang R, Ye F, Yang Z, Wang Z, Shi F, Tan W (2021) What medical waste management system may cope with COVID19 pandemic: lessons from Wuhan. Resour Conserv Recycl 170:105600. https://doi.org/10.1016/j.resconrec.2021.105600

CPCP (Central Pollution Control Board of India) (2020) Guidelines for handling, treatment and disposal of waste generated during treatment/diagnosis/quarantine of COVID-19 patients. Accessed on Oct 20, 2021. Available at: https://covidlawlab.org/wp-conte nt/uploads/2021/01/India_2020.03.25_Guidelines-for-HandlingTreatment-and-Disposal-of-Waste-Generated-during-Treatmentor-Diagnosis-or-Quarantine-of-COVID-19-patients_EN.pdf

Das AK, Islam MN, Billah MM, Sarker A (2021) COVID-19 pandemic and healthcare solid waste management strategy - A mini-review. Sci Total Environ 778:146220. https://doi.org/10.1016/j.scitotenv. 2021.146220

Dias-Ferreira C, Santos T, Oliveira V (2015) Hospital food waste and environmental and economic indicators - a Portuguese case study. Waste Manage 46:146-154. https://doi.org/10.1016/j.wasman. 2015.09.025

Elsaid K, Olabi V, Sayed ET, Wilberforce T, Abdelkareem MA (2021) Effects of COVID-19 on the environment: An overview on air, water, wastewater, and solid waste. J Environ Manage 292:112694. https://doi.org/10.1016/j.jenvman.2021.112694

Fletcher CA, St. Clair R, Sharmina M (2021) A framework for assessing the circularity and technological maturity of plastic waste management strategies in hospitals. J Cleaner Prod 306:127169. https://doi.org/10.1016/j.jclepro.2021.127169

Ganguly RK, Chakraborty SK (2021) Integrated approach in municipal solid waste management in COVID-19 pandemic: perspectives of a developing country like India in a global scenario. Case Stud Chem Environ Eng 3:100087. https://doi.org/10.1016/j.cscee. 2021.100087

Ghosh A, Ng KTW (2021) Temporal and spatial distributions of waste facilities and solid waste management strategies in rural and urban
Saskatchewan Canada. Sustainability 13:6887. https://doi.org/10. $3390 /$ su 13126887

Government of India (2021) Delhi Covid updates. Accessed on Oct 2, 2021. Available at: http://corona.delhi.gov.in/covid-delhi-data/

Government of UK (2021) Guidance on prioritising waste collection services during coronavirus (COVID-19) pandemic. Accessed on Oct 21, 2021. Available at: https://www.gov.uk/government/ publications/coronavirus-covid-19-advice-to-local-authoritieson-prioritising-waste-collections/guidance-on-prioritisingwaste-collection-services-during-coronavirus-covid-19-pande mic

Hantoko D, Li X, Pariatamby A, Yoshikawa K, Horttanainen M, Yan M (2021) Challenges and practices on waste management and disposal during COVID-19 pandemic. J Environ Manage 286:112140. https://doi.org/10.1016/j.jenvman.2021.112140

Ilyas S, Srivastava RR, Kim H (2020) Disinfection technology and strategies for COVID-19 hospital and bio-medical waste management. Sci Total Environ 749:141652. https://doi.org/10.1016/j. scitotenv.2020.141652

Keller RL, Muir K, Roth F, Jattke M, Stucki M (2021) From bandages to buildings: identifying the environmental hotspots of hospitals. J Clean Prod 319:128479. https://doi.org/10.1016/j.jclepro.2021. 128479

Kulkarni BN, Anantharama V (2020) Repercussions of COVID-19 pandemic on municipal solid waste management: challenges and opportunities. Sci Total Environ 743:140693. https://doi.org/10. 1016/j.scitotenv.2020.140693

Mallapur C (2020) Sanitation workers at risk from discarded medical waste related to COVID-19. Accessed on Oct 4, 2021. Available at: https://www.indiaspend.com/sanitation-workers-at-risk-fromdiscarded-medical-waste-related-to-covid-19/

Manupati VK, Ramkumar M, Baba V, Agarwal A (2021) Selection of the best healthcare waste disposal techniques during and post COVID-19 pandemic era. J Clean Prod 281:125175. https://doi. org/10.1016/j.jclepro.2020.125175

Olatayo KI, Mativenga PT, Marnewick AL (2021) COVID-19 PPE plastic material flows and waste management: quantification and implications for South Africa. Sci Total Environ 790:148190. https://doi.org/10.1016/j.scitotenv.2021.148190

Penteado CSG, Castro MASD (2021) Covid-19 effects on municipal solid waste management: what can effectively be done in the Brazilian scenario? Resources Conserv Recycl 164:105152. https:// doi.org/10.1016/j.resconrec.2020.105152

Purnomo CW, Kurniawan W, Aziz M (2021) Technological review on thermochemical conversion of COVID-19-related medical wastes. Resour Conserv Recycl 167:105429. https://doi.org/10. 1016/j.resconrec.2021.105429

Ramteke S, Sahu BL (2020) Novel coronavirus disease 2019 (COVID19) pandemic: considerations for the biomedical waste sector in India. Case Stud Chem Environ Eng 2:100029. https://doi.org/10. 1016/j.cscee.2020.100029

Richter A, Ng KTW, Karimi N (2019) A data driven technique applying GIS, and remote sensing to rank locations for waste disposal site expansion. Resour Conserv Recycl 149:352-362. https://doi. org/10.1016/j.resconrec.2019.06.013

Richter A, Ng KTW, Vu HL, Kabir G (2021a) Identification of behaviour patterns in waste collection and disposal during the first wave of COVID-19 in Regina, Saskatchewan Canada. J Environ Manag 290:112663. https://doi.org/10.1016/j.jenvman.2021.112663

Richter A, Ng KTW, Vu HL, Kabir G (2021b) Waste disposal characteristics and data variability in a mid-sized Canadian city during COVID-19. Waste Manage 122:49-54. https://doi.org/10.1016/j. wasman.2021.01.004

Silva PAL, Prata JC, Walker TR, Campos D, Duarte AC, Soares AMVM, Barcelò D, Rocha-Santos T (2020) Rethinking and optimising plastic waste management under COVID-19 pandemic: 
policy solutions based on redesign and reduction of single-use plastics and personal protective equipment. Sci Total Environ 742:140565. https://doi.org/10.1016/j.scitotenv.2020.140565

Somani M, Srivastava AN, Gummadivalli SK, Sharma A (2020) Indirect implications of COVID-19 towards sustainable environment: an investigation in Indian context. Bioresource Technology Reports 11:100491. https://doi.org/10.1016/j.biteb.2020.100491

SWANA (Solid Waste Association of North America) (2020) SWANA reminds all states and local governments that solid waste management is an essential public service. Accessed on Oct 1, 2021. Available at: https://swana.org/news/swana-news-archive/article/ 2020/03/19/swana-reminds-all-state-and-local-governments-thatsolid-waste-management-is-an-essential-public-service

Thind PS, Sareen A, Singh DD, Singh S, John S (2021) Compromising situation of India's bio-medical waste incineration units during pandemic outbreak of COVID-19: associated environmental-health impacts and mitigation measures. Environ Pollut 276:116621. https://doi.org/10.1016/j.envpol.2021.116621

Torres FG, De-la-Torre GE (2021) Face mask waste generation and management during the COVID-19 pandemic: an overview and the Peruvian case. Sci Total Environ 786:147628. https://doi.org/ 10.1016/j.scitotenv.2021.147628

Valizadeh J, Aghdamigargari M, Jamali A, Aickelin U, Mohammadi S, Khorshidi HA, Hafezalkotob A (2021) A hybrid mathematical modelling approach for energy generation from hazardous waste during the COVID-19 pandemic. J Clean Prod 315:128157. https://doi.org/10.1016/j.jclepro.2021.128157

Vu HL, Ng KTW, Fallah B, Richter A, Kabir G (2020) Interactions of residential waste composition and collection truck compartment design on GIS route optimization. Waste Manage 102:613-623. https://doi.org/10.1016/j.wasman.2019.11.028

Vu HL, Ng KTW, Richter A, Kabir G (2021a) The use of a recurrent neural network model with separated time-series and lagged daily inputs for waste disposal rates modeling during COVID-19. Sustain Cities Soc 75:103339. https://doi.org/10.1016/j.scs.2021. 103339
Vu HL, Ng KTW, Richter A, Karimi N, Kabir G (2021b) Modeling of municipal waste disposal rates during COVID-19 using separated waste fraction models. Sci Total Environ 789:148024. https://doi. org/10.1016/j.scitotenv.2021.148024

Wang J, Chen Z, Lang X, Wang S, Yang L, Wu X, Zhou X, Chen Z (2021) Quantitative evaluation of infectious health care wastes from numbers of confirmed, suspected and out-patients during COVID-19 pandemic: a case study of Wuhan. Waste Manag 126:323-330. https://doi.org/10.1016/j.wasman.2021.03.026

Wang Z, Guy C, Ng KTW, An C (2021b) A new challenge for the management and disposal of personal protective equipment waste during the COVID-19 Pandemic. Sustainability 13:7034. https:// doi.org/10.3390/su13137034

Weather \& Climate (2021) Average day and night temperature in New Delhi in celsius accessed on https://weather-and-climate.com/ average-monthly-min-max-Temperature,New-Delhi,India by 2021/Oct/03

Worldometers (2021a) COVID-19 Coronoavirus pandemic. Accessed on Oct 21, 2021a. Available at: https://www.worldometers.info/ coronavirus/

Worldometers (2021b) India population. Accessed on Oct 21, 2021 b. Available at: https://www.worldometers.info/world-population/ india-population/

Worldpopulationreview (2021) Largest metro areas in the world. Accessed on Oct 21, 2021. Available at: https://worldpopulation review.com/world-city-rankings/largest-metro-areas-in-the-world

Yang L, Yu X, Wu X, Wang J, Yan X, Jiang S, Chen Z (2021) Emergency response to the explosive growth of health care wastes during COVID-19 pandemic in Wuhan, China. Resour Conserv Recycl 164. https://doi.org/10.1016/j.resconrec.2020.105074

Publisher's note Springer Nature remains neutral with regard to jurisdictional claims in published maps and institutional affiliations. 